\title{
VOORGESKIEDENIS TOT DIE STIGTING VAN 'N UNIEVERDEDIGINGSMAG
}

\author{
Lt (SAV) E.M. Meyers*
}

\section{Ontstaan van 'n verdedigingstelsel}

Die voorgeskiedenis van die Suid-Afrikaanse Weermag kan teruggevoer word tot aan die begin van die geskiedenis van die blanke volksplanting aan Tafelbaai. Reeds op 9 April 1652 het Jan van Riebeeck aan boord van die 'Drommedaris' 'n reglement vir soldate en offisiere uitgevaardig. Die bou van 'n fort, asook die feit dat die kommandeur van 'n garnisoenmag van ongeveer sewentig vergesel was, lewer bewys van die vaste wil van die opdraggewers om die jong nedersetting teen moontlike aanslae van buite, sowel as teen moontlike vyandiggesinde inboorlinge te verdedig.

Die klein blanke nedersetting wat op 'n belangrike skeepvaartroete tussen die ooste en die weste geleë was, is ter wille van handelsbelange verdedig. Aanvanklik was die verdediging die taak van Kompanjiesdienare wat die garnisoen uitgebrei het deur honderde soldate van die Hollandse skepe af te kry. Afgesien van die garnisoensoldate moes die manlike burgers militêre diens doen en ses jaar na die aankoms van Van Riebeeck is al die weerbare Vryburgers reeds in 'n skutterskompanie ingedeel. Vryburgers en hul nasate het na die binneland begin uitstroom en die burgermilisiestelsel met sy beginsel van persoonlike diensplig het tot ontplooiïng gekom. Die uitbreiding van die kolonie het die stigting van berede eenhede genoodsaak sodat groter mobiliteit verkry kon word.

Na verloop van tyd het die kommandostelsel die belangrikste weerbare organisasie geword waaroor die kolonie beskik het. Met offisiere wat uit eie geledere gekies is, het die mobiele wag tot 'n nasionale organisasie uitgekring. Vir alle burgers tussen 16 en 60 was militêre diens verpligtend. In teenstelling met die Kaapse garnisoen, wat ongetwyfeld die belange van hulle here en meesters in gedagte gehad het, was die handhawing en verdediging van hul eie belange deur die kommandolede as vernaamste taak beskou.

\section{Kaapkolonie tot 1912}

Die 19de eeuse verdedigingsorganisasie van die Kaapkolonie is met die intrede van die Britse militêre tradisie radikaal verander. Vrywilligereenhede het die kommando's van weleer begin vervang en gereelde troepe is uit Engeland na die kolonie gestuur. Britse eenhede het in die Kaapkolonie skouer aan skouer met vrywilligers geveg. Die 'Cape Mounted Riflemen' wat die eintlike koloniale Staandemag was, het in 1855 as die 'Frontier Armed and Mounted Police' begin en het in 1878 die 'Cape Mounted Riflemen' (CMR) geword. Na die Tweede Vryheidsoorlog is offisiere van die CMR met die opleiding van Kaapse vrywilligereenhede belas.

Die CMR het in 1913 die eerste regiment 'ZuidAfrikaansche Bereden Schutters' of 'South African Mounted Rifles' geword wat deel van die Unieverdedigingsmag was. Die sterkte van die Kaapse strydkragte ten tye van die Durbanse Verdedigingskonferensie van 1908 was: Die 'Cape Mounted Rifles' - 517 berede troepe en 60 artilleriste; Die Vrywilligereenhede - 870 be-

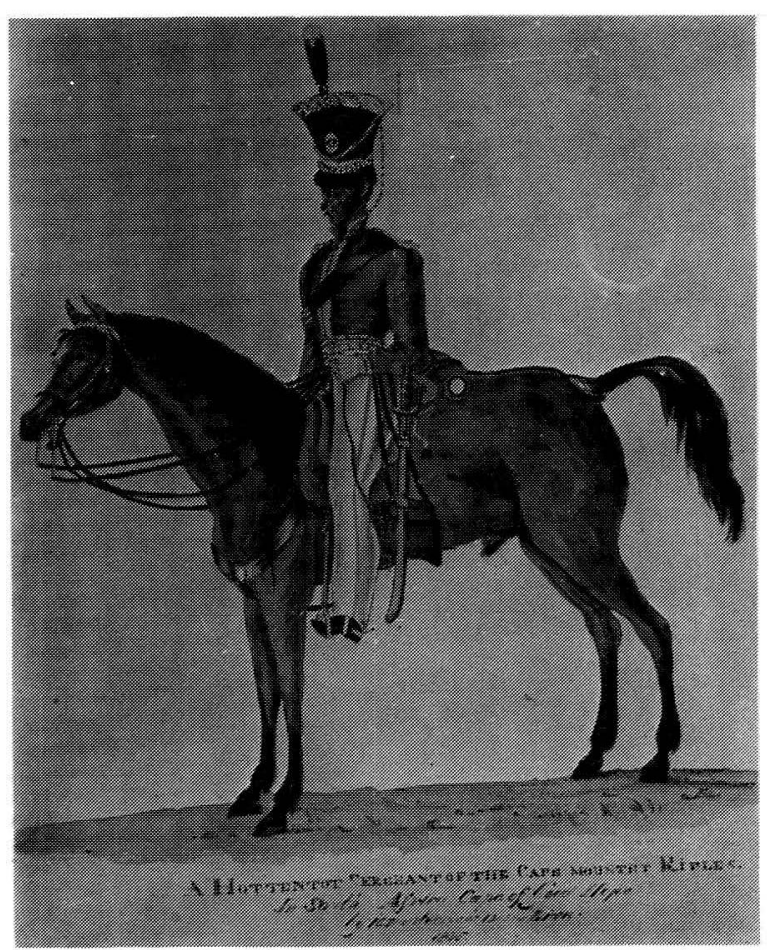

'n Hottentot-Sersant (Pandoer) van die Cape Mounted Rifles 
rede troepe, 133 artilleriste, 2395 infanteriste en 100 lede van die mediese afdeling; die polisie 500 berede lede.

\section{Natal (1840-1912)}

Die georganiseerde verdediging van Natal kan teruggevoer word na die kortstondige bestaan van die Voortrekkerrepubliek Natalia (1840-43) waar die kommandostelsel as grondslag daargestel is en elke wyk onder 'n veldkornet en elke distrik onder 'n kommandant ingeskakel het met as opperbevelhebber die kommandant-generaal wat slegs in geval van oorlog sou optree en nie ' $n$ vaste pos beklee het nie. Die eerste persoon om dié pos in Natal te beklee, was die Trekkerleier, Andries Pretorius. Na die anneksasie van die gebied deur Engeland het die verdedigingstaak van die kolonie dié van agtereenvolgende Britse militêre eenhede geword.

Vrywilligerorganisasies soortgelyk aan dié in die Kaapkolonie het in Natal posgevat en in 1854 het die 'Natal Artillery' ontstaan wat as kompanie van die 'Durban Volunteer Guard' begin het. In dieselfde verband kan die 'Royal Natal Carbineers' (1855) en die 'Victoria Mounted Rifles' van die vroeë sestigerjare genoem word. As 'n uitvloeisel van die toekenning van verantwoordelike bestuur aan die kolonie in 1893, het die Natalse regering geleidelik die verantwoordelikheid vir die verdediging van die grondgebied oorgeneem

Mobilisasie vir die vrywilligereenhede het op werwing berus. In 1903 is die bestaande wet deur die Milisiewet vervang waarvolgens Natal 'n stelsel verkry het waarvolgens die sterkte, indien nodig, deur loting aangevul is. Wat die reserwes betref, was die nuwe organisasie sterk deur die kommandostelsel beïnvloed. Die milisie het sy vuurproef met die Zoeloe-opstand van 1906 goed deurstaan. Hoewel die vredestydse sterkte van die milisie op 4000 bepaal is, was daar op 7 Mei 1906 ruim 4316 man in die veld. Bekende eenhede was: die 'Natal Carbineers', die 'Natal Mounted Rifles', die 'Durban Light Infantry' en die 'Natal Field Artillery' asook die 'Natal Naval Corps' en die 'Natal Police'.

In 1908 was die sterkte van die Natalse verdedigingsorganisasies soos volg: Milisie -1380 berede lede, 251 artilleriste, 687 infanteriste, 30 seiners en telegrafiste en 74 lede van die mediese afdeling: Natalse polisie -774 berede polisiemanne en 286 voetpolisie

\section{Oranje-Vrystaat (1854-1912)}

Met die totstandkoming van die Vrystaatse Republiek in 1854 is geen voorsiening vir ' $n$ departement van oorlog gemaak nie. Gedurende vredestyd was daar nie eers 'n opperbevelhebber nie. Die kommandostelsel is desnieteenstaande behou en militêre- of burgerdiens was verpligtend vir burgers tussen die ouderdomme van 16 tot 60 jaar. Ten tye van oorlog het die president oor 'n kommandant-generaal - meesal hoofkommandant genoem - beskik.

Die militêre organisasie van die Vrystaat in die oorloë teen die Basoetoes was redelik effektief aangesien die Vrystaatse regering spoedig na onafhanklikheid aan die organisasie van sy strydkragte begin dink het. Die eerste kommandowet is al in Mei 1854 gepubliseer. President Boshof, 1855-1859, het op die invoering van tradisionele wapenskouings aangedring en kanonne aangekoop en in 1864 het pres Brand $£ 1000$ op die begroting geplaas vir ' $n$ 'rijdende artillerie van 20 manschappen' wat deur die president vir die beskerming van die inwoners aangewend kon word.

Die Vrystaat het van 1889-1896 oor die 'Rijdende Dienstmacht' beskik wat aanvanklik los van die artilleriekorps was. In 1896 is hierdie organisasie onder die Vrystaatse kommissaris van polisie geplaas en was dit hoofsaaklik met patrolliewerksaamhede belas.

Gedurende die oorlogsjare het die verdedigingsorganisasies van die twee Boere-republieke verdwyn en die 'South African Constabulary' het sy intrede in ons militêre geskiedenis gedoen. Teen 1908 het die polisiemag in die Vrystaat uit 251 berede polisiemanne en 156 voetpolisie bestaan.

\section{Zuid-Afrikaansche Republiek (1852-1912)}

Met die bekende drie-en-dertig artikels van Potchefstroom wat op 23 Mei 1849 op Derdepoort goedgekeur is, is die grondslag van die verdedigingsaangeleenthede van die Zuid-Afrikaansche Republiek gelê. Volgens bepaling sou elke offisier van die gewapende mag dezer maatschappij' wat sou weier om aan 'n wettige oproep deur die Raad of burgerlike gesag gehoor te gee, met 'n geldboete of tronkstraf gestraf word.

In die Transvaalse Republiek is die kommandostelsel behou met die belangrike verskil dat die 
kommandant-generaal 'n spesifieke rol gehad het. Hy was lid van die Uitvoerende Raad asook hoof van die burgermagte wat bestaan het uit alle weerbare mans van die republiek tussen 16 en 60 en - indien nodig - kon nie-blankes ook vir militêre diens opgeroep word. Net soos in die Vrystaat moes die Transvaalse burgers hul eie wapens verskaf en is nie vir hulle dienste vergoed nie.

Die Zuid-Afrikaansche Republiek het na verloop van tyd oor ' $n$ staandemag, die Staatsartilleriekorps, beskik. Die grondslag is in die sewentigerjare gelê, en na reorganisasie van die korps in 1896 het dit 'n tydperk van vooruitgang beleef.

Die Transvaalse polisiemag, die 'Zuid-Afrikaansche Republiek Politie' (ZARP) het in 1898 uit 1348 berede lede en voetpolisie bestaan, terwyl 170 polisiemanne in Swaziland onder beheer van die Transvaalse kommissaris gestasioneer was

Hoewel die Britse vrywilligerstelsel van die jare 1902-1912 geen ingang in die Oranjerivierkolonie gevind het nie, is die 'Transvaal Volunteer' organisasie in dié tyd daargestel. In dieselfde jaar het die volgende vrywilligereenhede in Johannesburg ontstaan: die 'Imperial Light Horse', die 'South African Light Horse', en die 'Scottish Horse'.

In 1908 het Transvaal oor 1620 berede vrywilligers, 125 artilleriste, 1080 infanteriste, 500 lede van die genie, 50 seiners en telegrafiste en 200 lede van die mediese afdeling beskik. Die polisiemag het terselftertyd uit 889 berede polisiemanne en 1060 voetpolisie bestaan. Die swaartepunt van die gewapende magte in 1908 was gewis noord van die Vaalrivier gewees

\section{Strewe na interkoloniale samewerking}

Dit sou verkeerd wees om te veronderstel dat militêre samewerking op 'n landswye grondslag eers na Uniewording in 1910 vir die eerste keer oorweeg is. Met die Zoeloe-onluste in 1906 is bewys dat interkoloniale samewerking in verdedigingsaangeleenthede noodsaaklik is.

In 1907 het verteenwoordigers van die vier kolonies sowel as die administrateur van Suid-Rhodesië in Johannesburg konferensie gehou. Hier is die koloniale bydraes tot ' $n$ voorgestelde interkoloniale troepemag as volg saamgestel: Die Kaapkolonie - 1500, Transvaal - 1 000, Natal -
500, die Oranjerivierkolonie - 500 en Suid-Rhodesië - 200 .

'n Jaar later is daar in Durban verder hierop ingegaan. Die belangrikheid van militêre samewerking tussen die Britse Ryk en Suidelike Afrika asook die beginsel van eenvormige militêre benamings en indelings het op dié geleentheid aandag geniet. Die daarstelling van ' $n$ kollege vir die opleiding van offisiere sowel as reserweskietverenigings is aanbeveel.

In dieselfde jaar het genl lord Methuen verklaar dat omstandighede daartoe kan lei dat Brittanje sy troepe aan Suid-Afrika moet onttrek en dat net die Kaapse Skiereiland deur Imperiale troepe verdedig sou word. 'n Imperiale verdedigingskonferensie is in 1909 in Londen gehou waar besluit is dat al die lede van die Britse Ryk bydraes tot die algemene ryksverdediging sou lewer.

\section{Eerste jare na Uniewording (1910)}

Met die totstandkoming van die Unie is 'n nuwe tydperk ingelui. Die daarstelling van 'n nuwe verdedigingsorganisasie was ongetwyfeld een van die belangrikste take wat die Botha-kabinet in die gesig gestaar het. Op 31 Mei 1910 het genl J.C. Smuts die portefeuljes van Binnelandse Sake, Mynwese en Verdediging begin beheer en tot 1 Julie 1912 is die administrasie van verdedigingsaangeleenthede deur ' $n$ tak van die Departement van Binnelandse Sake behartig.

Die aanloop tot die Verdedigingswet van 1912 sowel as die vurige botsing van opinies wat daarmee saamgegaan het, kan as die geboortepyne van die Unieverdedigingsmag beskou word.

In 1909 het genl C.F. Beyers algemene diensplig op 'n konferensie van die Suid-Afrikaanse Vroue Federasie bepleit en toe daar in 1911 aanstaltes gemaak is om ' $n$ verdedigingswet vir die Unie op te stel, was daar min mense wat die loop van sake met groter belangstelling gevolg het as genl Beyers.

In Julie 1911 het J.X. Merriman uit Londen aan Smuts i.s. die verdedigingswetgewing geskryf dat hy sal moet besluit hoeveel hy bereid is om op verdediging te bestee en daarvolgens bepaal watter soort staandemag die Unie sal hê. Hy het hom uit gespreek ten gunste van 'n 
kleiner dog beter opgeleide en gedissiplineerde aantal soldate pleks van 'n groot aantal onbehoorlik georganiseerde burgers. Algemene opleiding, behalwe op 'n onafgeronde en onvolmaakte wyse, sou volgens Merriman te duur wees. Een van die belangrikste punte van kritiek op die wet was dat algemene opleiding plek moes maak vir gespesialiseerde opleiding en die volk as geheel dan nie so paraat sou wees nie. Merriman het verder aan Smuts geskryf dat die infanterie die land se swak skakel in sy wapenrusting was. Hoewel hy seker was dat die land enige naturelle-inval kon weerstaan, moes hy waak teen 'n staatsgreep van buite.

Smuts het die verdedigingswetsontwerp aan pres M.T. Steyn gestuur vir kommentaar en het in Desember 1911 Steyn se antwoord daarop ontvang. Sy opinie was dat veel van die wyse van uitvoering van die wet afhang. Die kadette kon weggelaat word, aangesien studie en sport op sigself al genoeg tyd van die kinders verg. Hy het verder gevrees dat die kadette-stelsel militarisme sou aankweek wat syns insiens noodlottig vir ' $n$ volk is en daartoe bydra om landsverdediging te verswak. Met die lotingstelsel het hy nie volkome saamgestem nie - weer 'n algemene knelpunt in die wet. Hy begryp dat dit ingevoer is omrede finansiële oorwegings, hoewel die ou Republikeinse metode beter was om elke weerbare man tussen 16 en 23 jaar te verplig om oefeninge te ondergaan. Steyn beweer dat niemand die reg moet hê om hom los te koop nie en dat elke burger moes weet dat hy sou moes veg ingeval 'n oorlog uitbreek.

In 'n brief aan pres Steyn op 23 Desember 1911 het Smuts Steyn bedank vir die waardevolle op-

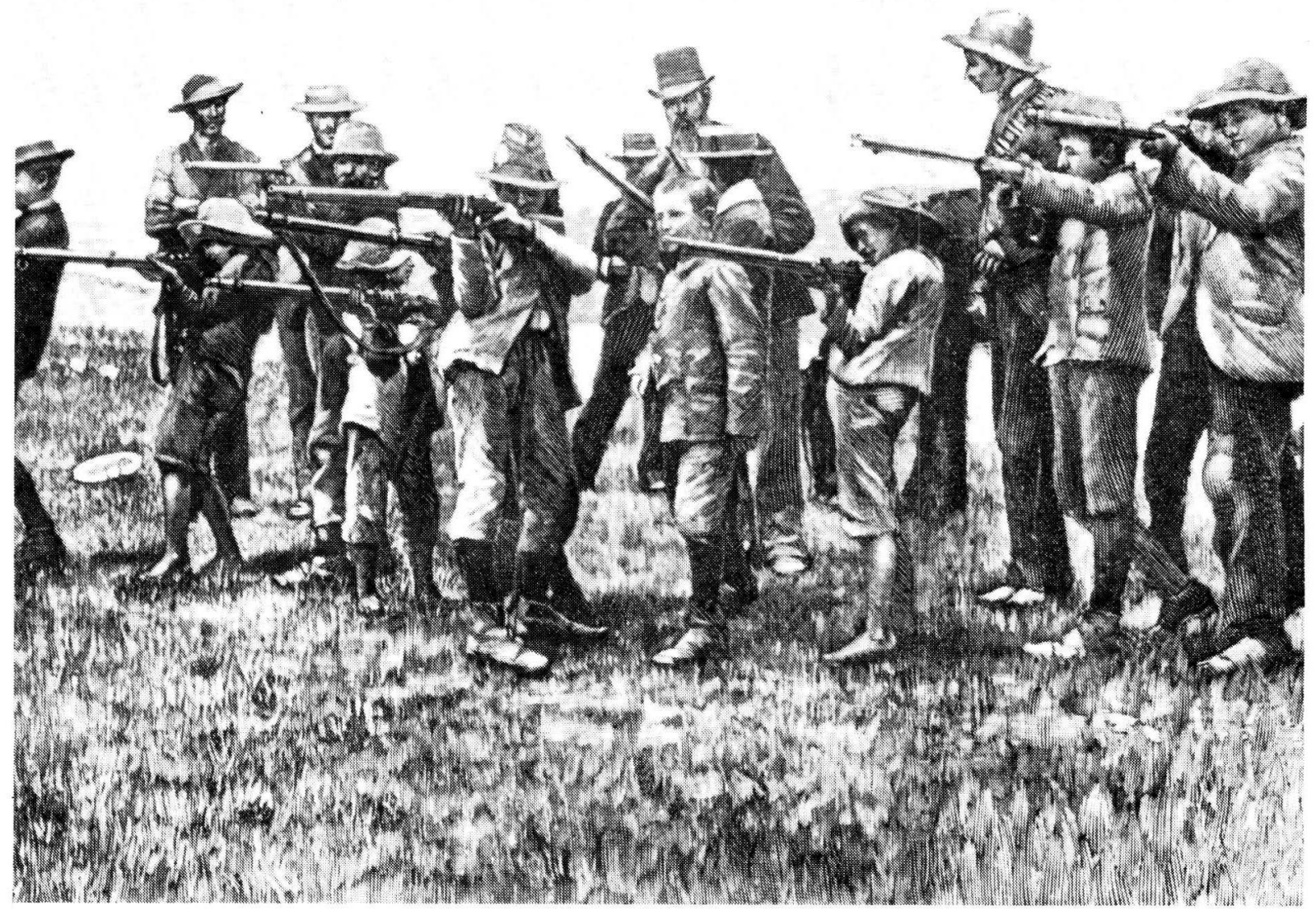

Boerseuns besig om deel te neem aan 'n skietoefening 
merkings oor die wetsontwerp en erken dat die president sy vinger op die moeilike punte gelê het waaroor Smuts baie besprekings in die parlement verwag het.

Op 14 Januarie 1912 skryf M.T. Steyn weer aan genl Smuts dat hy saamstem dat Bloemfontein die geskikte middelpunt vir ' $n$ militêre kollege asook vir 'n groot deel van die aktiewe leërmag is.

Genl C.F. Beyers het die verdediging van die land nie in dieselfde lig as genls Botha en Smuts gesien nie en toe die wetsontwerp op 23 Februarie 1912 deur Smuts in sy hoedanigheid as Minister van Verdediging ingedien is, het Beyers heelwat kritiek daarop gehad. Beyers het beweer dat dit op vergaderings geblyk het dat die volk wou hê Engeland moet steeds die verdediging waarneem aangesien die Unie onder Engeland se beskerming was. ' $n$ Verdere argument wat Beyers aangevoer het, was dat daar in Engeland geen dwang tov verdediging was nie en die volk wou weet waarom dwang hier te lande toegepas moes word

'n Belangrike punt wat Beyers benadruk het, was dat as die wetsontwerp 'n sukses wou wees, dit belangrik was dat mense mekaar goed verstaan en onderlinge respek vir tradisies en gevoelens moes bestaan. Verder in verband hiermee is Smuts oor die kole gehaal omdat hy nie met die opstelling van die wet die ou offissiere en manskappe van die Republieke se mening ingewin het insake die grondslag waarop die verdedigingstelsel gebaseer moes word nie. Instede hiervan het hy Engelse offissiere wel geraadpleeg om tot ' $n$ basis vir die wet te kom. Die ontwerp is dus te veel op ' $n$ vreemde lees geskoei en is gebaseer op stelsels wat van ander lande oorgeneem is.

As teenvoeter vir die vreemde, meld Beyers dat daar in die ontwerp gewag gemaak is van skietverenigings as nasionale instellings, wat wanneer dit ontwikkel word, 'n verdedigingstelsel daar sal stel wat met die aard van die volk ooreenkom. Hy sou wou sien dat alle jongmanne tussen 21 en 25 jaar verplig word om by skietverenigings aan te sluit.

Nog 'n punt in die wetsontwerp waarmee Beyers hom nie kon vereenselwig nie, was dié van militêre oefeninge. Oefeninge is belangrik, maar die duur van die oefentyd moes nie per regulasie geskied nie, maar volgens wet waarin ' $n$ vasgestelde aantal dae per jaar neergelê is. Oefe- ninge moes algemeen gemaak word en die hele volk moes daarby betrek word. Op die punt is Steyn en Beyers dit weer eens. So ook vrees Beyers dat die Boer in militarisme sal verval en dat sy inisiatief daaronder sal ly.

Wat die lotingstelsel betref, het Beyers geglo dat as daar dwang moet wees, dit algemeen moet wees. Loting het 'n verderflike invloed op vaderlandsliefde en persoonlike verantwoordelikheid. Hy bepleit ' $n$ meer uitgebreide leër as die voorgestelde 25000 . Hy sou verkies dat die verdedigingsmag sowat 300000 man sterk moet wees.

Wat artillerie betref, was baie oefeninge nodig aangesien dit ' $n$ hoogs tegniese korps is. Hy was ' $n$ voorstander daarvan dat soveel moontlik burgers met kanonne moes leer skiet. In 'n noodtoestand moes daar altyd iemand wees wat met 'n kanon kan skiet.

Die staandemag sou gevorm word uit die bestaande polisie. Dis egter jammer dat die twee gevegsdele, polisie en artillerie of staandemag. onder verskillende hoofde val. Hy is daarop teë dat die artillerie dus ook polisiewerk sal moet doen.

Hy stel voor dat die reserwe 'n afsonderlike eenheid met sy eie offisiere sal vorm. Die nasionale reserwe kan nie soos bepaal, diens doen by die eenheid waarby dit aangewys is nie, aangesien die reserwe heeltemal ongeorganiseer en ongeoefen is. Hulle kan nie by geoefende troepe ingelyf word nie, want hulle sal net verwarring veroorsaak.

Hy voel sterk oor die invoer van 'n taalklousule ivm die opleiding van manskappe deur 'n offisier wat dieselfde taal praat sover praktiese moontlik. Dit sou daarop neerkom dat 'n Hollandse offisier oor die Hollandssprekendes aangestel moet word.

Beyers spreek hom uit teen die Raad van Verdediging wat die Minister moes adviseer en dus tussen hom en die Kommandant-generaal sou staan. In die ou stelsel het die Kommandantgeneraal sy bevele direk van die regering ontvang. Hy vrees dat die raad te veel invloed sou bekom en 'n greep op die publiek sou kry. Ingeval van oorlog, is sy ondervinding dat 'n mens op die generaal moet vertrou. 


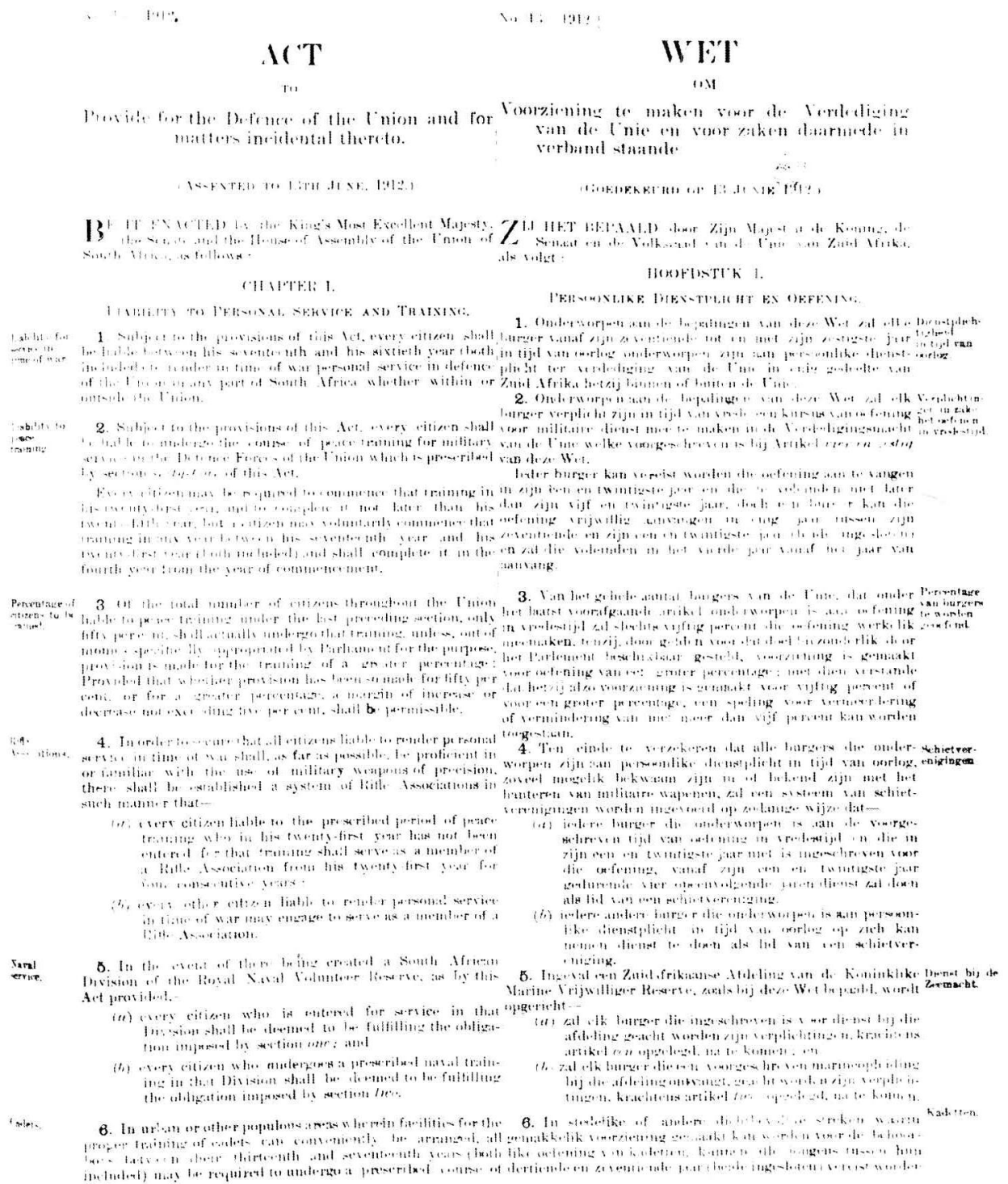

Daar is besluit dat Beyers die man was wat die Aktiewe Burgermag sou lei, aangesien hy, afgesien van die Eerste Minister genl Botha, die enigste was van wie die hele volk die verdedigingswet sou aanneem. Genl Beyers, die groot teenstander van die wet het op 1 Julie 1912 die eerste Kommandant-generaal van die Burgermag geword. Vanaf laasgenoemde datum het die Departement van Verdediging as 'n afsonderlike departement begin funksioneer met die latere sir Ronald Bourne as Sekretaris.

In die wet is voorsiening gemaak vir 'n klein Staandemag van sowat 26000 man, 'n groot aantal berede troepe en 'n Aktiewe Burgermag wat uit vrywilligers gewerf is en aangevul is deur stemgeregtigdes en ' $n$ burgerreserwemag wat in skietverenigings georganiseer is.
Ofskoon verdere verdedigingswetgewing gevolg het, bly die wet van 1912 nog wat die beginsels betref, die stewige fondament waarop die huidige verdedigingsorganisasie bekend as die Suid-Afrikaanse Weermag, rus.

* Lt (SAV) E.M. Meyers, MA, is verbonde aan die Militere Informasieburo van die SAW.

\section{Bronne}

J. Ploeger, Op Brandwag - Drie Eeue Militêre Geskiedenis van Suid-Afrika. 1968.

Standard Encyclopaedia of South Africa, vol 7. Cape Town. 1972.

A.J. Böeseken. Die Nederlandse Kommissarisse en die 18de eeuse samelewing van die Kaap, Kaapstad. 1945.

P.E. Roux, die Verdedigingstelsel aan die Kaap onder die Hollands Oosindiese Kompanjie (1652-1759). Stellenbosh, 1925

G. Tylden, The Armed Forces of South Africa, Johannesburg, 1945.

G.D. Scholtz. Generaal Christiaan Frederik Beyers 1869-1914, Johannesburg, 1941.

W.K. Hancock and Jean van der Poel, Selections from the Smuts Papers, Vol III, June 1910 - November 1918, Cambridge, 1966. 